\title{
A Study of Pain after Conservative Management of Degenerative Disease of Lumbar Spine
}

\author{
Dr Harikiran Bangera
}

Assistant Professor, Department of Orthopedics, Srinivas Institute of Medical Sciences, Mangalore.

\begin{abstract}
The most common diagnosis is the degenerative diseases of the lumbar spine. This is because of the Anatomical curves. When a rigid curve meets a moving curve the point at which the change occurs often forms the weakest point. Lower backache in today's world is very commonly complained in every age group but more commonly in the eldersSo in today's world where the posture of the body when is not maintained well forms these forms of anomaly. There is a great debate among the authors of which is the most ideal mode of treatment. So this study tries to highlight the same.
\end{abstract}

Keywords: Conservative management, Surgical Management, Lumbar Spine, Canal Stenosis

\section{Introduction}

Zaina $\mathrm{F}^{1}$, Tomkins-Lane C, Carragee E, Negrinihave very little confidence to conclude whether surgical treatment or a conservative approach is better for lumbar spinal stenosis. However, it was noted that the rate of side effects ranged from $10 \%$ to $24 \%$ in surgical cases, and no side effects were reported for any conservative treatment. No clear benefits were observed with surgery versus non-surgical treatment. These findings suggest that clinicians should be very careful in informing patients about possible treatment options, especially given that conservative treatment options have resulted in no reported side effects. Athiviraham et $\mathrm{al}^{2}$ prospectively evaluated 125 consecutive patients for this non-randomized cohort study. Of the patients choosing surgery, 54 underwent decompression only and 42 had decompression and fusion for preexisting spondylolisthesis; twenty-nine patients declined surgery. At 2 years followup, the average improvements in Roland-Morris questionnaire score in the decompression only, decompression with fusion, and nonsurgical groups were 6.9, 6.1, and 1.2, respectively. The percentages of patients who were better, worse, or the same were similar for those who had decompression only $(63.3 \%, 4.1 \%$, and $32.7 \%$, respectively) and decompression with fusion $(61.5 \%, 2.6 \%$, and $35.9 \%$, respectively) but different from those treated without surgery $(25.0 \%, 12.5 \%$, and $62.5 \%$, respectively). In today's world where the posture of the body when is not maintained well forms these forms of anomaly ${ }^{3-11}$.

This study tries to shed some light on the beneficial effects of the surgery in the above mentioned condition.

\section{Aims and Objectives of study}

To study pain after conservative mode of treatment available for degenerative diseases of the lumbar spine.

\section{Materials and Method}

This study was done inDepartment of Orthopedics, Srinivas Institute of Medical Sciences, Mangalore.

The study was done in 30 patients who were randomly selected.

\section{Inclusion criteria}

1. Degenerative Lumbar spine stenosis

Exclusion criteria

1. Pathological fractures

The statistical analysis was done using the latest SPSS 2015 California.

\section{Result}

Table 1: Age Distribution

\begin{tabular}{|c|c|}
\hline Age (years) & Number of Patients \\
\hline $30-40$ & 12 \\
\hline $40-50$ & 04 \\
\hline $50-60$ & 15 \\
\hline$>60$ & 09 \\
\hline
\end{tabular}

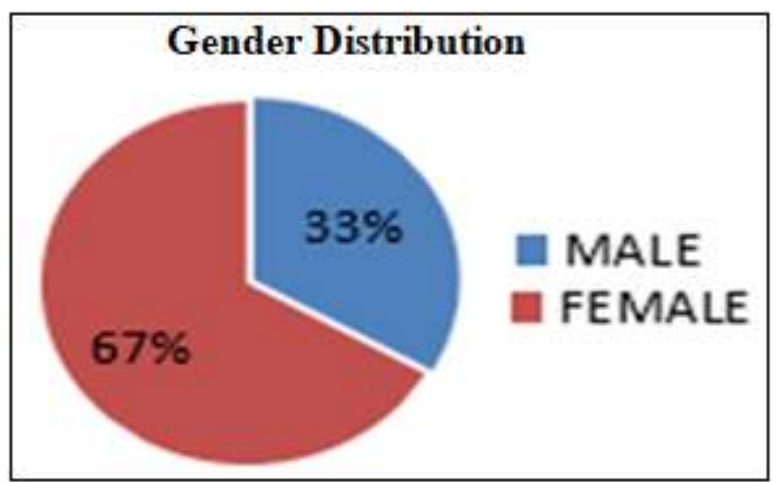

Graph 2: Gender Distribution

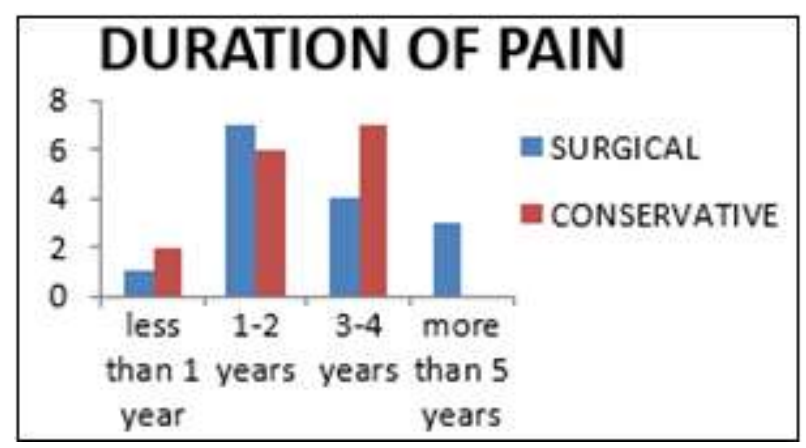

Graph 4: Duration of Pain when compared to the surgery: 


\section{International Journal of Science and Research (IJSR) \\ ISSN (Online): 2319-7064}

Index Copernicus Value (2016): 79.57 | Impact Factor (2015): 6.391

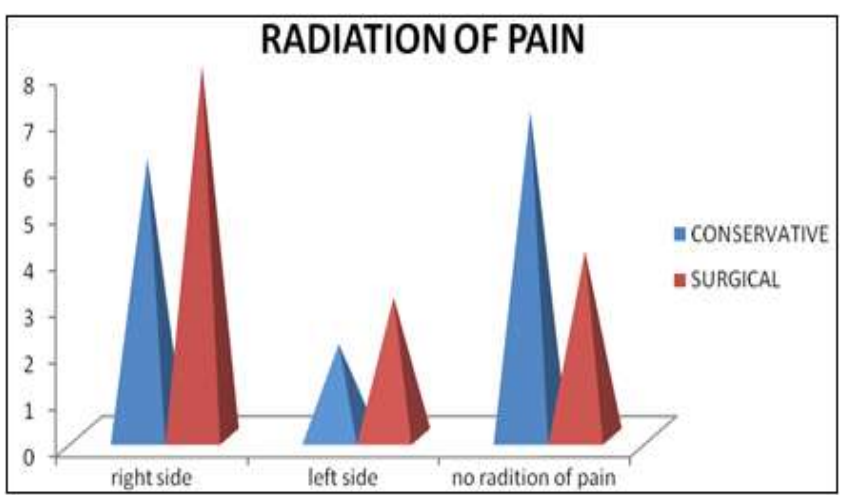

Graph 5: Radiation of Pain

\section{Discussion}

Malmivaara A et $\mathrm{al}^{13}$ studied 94 patients who were randomized into a surgical or nonoperative treatment group: 50 and 44 patients, respectively. Surgery comprised undercutting laminectomy of the stenotic segments in 10 patients augmented with transpedicular fusion. The primary pain (scales, 0-10), as well as self-reported and measured walking outcome was based on assessment of functional disability using the Oswestry Disability Index (scale, 0-100). Data on the intensity of leg and back ability were compiled at randomization and at follow-up examinations at 6,12, and 24 months.Both treatment groups showed improvement during follow-up. At 1 year, the mean difference in favor of surgery was 11.3 in disability (95\% confidence interval [CI], 4.3-18.4), 1.7 in leg pain (95\% CI, 0.4-3.0), and 2.3(95\% CI, 1.1-3.6) in back pain. At the 2-year follow-up, the mean differences were slightly less: 7.8 in disability (95\% CI, 0.814.9) 1.5 in leg pain (95\% CI, 0.3-2.8), and 2.1 in back pain (95\% CI, 1.0-3.3). Walking ability, either reported or measured, did not differ between the two treatment groups. Although patients improved over the 2-year follow-up regardless of initial treatment, those undergoing decompressive surgery reported greater improvement regarding leg pain, back pain, and overall disability. The relative benefit of initial surgical treatment diminished over time, but outcomes of surgery remained favorable at 2 years. Longer follow-up is needed to determine if these differences persist.Patients initially given a conservative line of management. If they are not better with the conservative modality like the pain is as of the same intensity or worsening during the course of treatment ${ }^{20}$.with support of the radiological investigation and of course clinical findings .the exact pathology of nerve root compression is identified and managed surgically with procedures like decompression, decompression with fusion or decompression fusion with instrumentation. This study didn't have any correlation with the signs and symptoms the pain wasn't associated with the neurological status the improvement of neurological status was better in the surgical group than in conservative group. The outcome of the surgical group was better when in patients who had pain for shorter duration.as the duration of pain increases it need not give a better result in form of outcome like pain and neurological status improvement. Patients under surgical group became better in relation to pain, claudication and neurological deficits than the conservative group for a follow up period of 6 months.

\section{Conclusion}

At 6 month follow up statistically significant difference $(\mathrm{p}=0.001)$ was noted as per Independent sample Mann Whitney $U$ test with respect to functionality among the two groups

\section{References}

[1] Athiviraham A, Yen D. Is spinal stenosis better treated surgically or nonsurgically? ClinOrthop. 2007 May;458:90-3.

[2] Malmivaara A, Slätis P, Heliövaara M, Sainio P, Kinnunen H, Kankare J, et al. Surgical or nonoperative treatment for lumbar spinal stenosis? A randomized controlled trial.Spine. 2007 Jan 1;32(1):1-8.

[3] Svensson HO, Andersson GB. Low-back pain in 40- to 47-year-old men: work history and work environment factors. Spine. 1983 Apr;8(3):272-6.

[4] Svensson HO, Andersson GB. The relationship of lowback pain, work history, work environment, and stress. A retrospective cross-sectional study of 38- to 64-year-old women. Spine. 1989 May;14(5):517-22.

[5] PFU Jr ,MD, Orthopedic Surgeon. Lumbar Spinal Stenosis: A Definitive Guide [Internet]. Spine-health. [cited 2016 Nov 25]. Available from: http://www.spinehealth.com/conditions/spinal-stenosis/lumbarspinalstenosis-a-definitive-guide

[6] Medtronic. Lumbar Spinal Stenosis Treatment \& Symptoms | Back.com [Internet]. [cited 2016 Nov 25]. Available from: http://www.back.com/backpain/conditions/lumbar-spinalstenosis/index.htm

[7] Ise S, Abe K, Orita S, Ishikawa T, Inage K, Yamauchi K, et al. Surgical treatment for far-out syndrome associated with abnormal fusion of the L5 vertebral corpus and L4 hemivertebra: a case report. BMC Res Notes [Internet]. 2016 Jun 28 [cited 2016 Nov 26];9. Available from: http://www.ncbi.nlm.nih.gov/pmc/articles/PMC4924308/

[8] Atlas SJ, Keller RB, Wu YA, Deyo RA, Singer DE. Long-term outcomes of surgical and nonsurgical management of lumbar spinal stenosis: 8 to 10 year results from the maine lumbar spine study. Spine. 2005 Apr 15;30(8):936-43.

[9] Caputy AJ, Luessenhop AJ. Long-term evaluation of decompressive surgery for degenerative lumbar stenosis. J Neurosurg. 1992 Nov 1;77(5):669-76.

[10] The Natural Course of Lumbar Spinal Stenosis. : Clinical Orthopaedics and Related Research [Internet]. LWW. [cited 2016 Dec 1]. Available from: http://journals.lww.com/corr/Fulltext/1992/06000/The_N atural_Cours e_of_Lumbar_Spinal_Stenosis_.10.aspx

[11] Yuan PS, Booth RE, Albert TJ. Nonsurgical and surgical management of lumbar spinal stenosis. Instr Course Lect. 2005;54:303-12.

[12] Roland Morris Disability Questionnaire [Internet]. [cited 2016 Dec 1]. Available from: http://www.rmdq.org/

[13] Weinstein JN, Lurie JD, Tosteson TD, Skinner JS, Hanscom B, Tosteson ANA, et al. Surgical vsnonoperative treatment for lumbar disk herniation: the Spine Patient Outcomes Research Trial (SPORT) observational cohort. JAMA. 2006 Nov 22;296(20):24519. 